\title{
British archaeology boost may uncover old enthusiasm
}

David Adam, London

Archaeologists are hoping that a $\mathfrak{1 . 2 -}$ million grant from the Leverhulme Trust will help to revive the study of ancient settlement patterns in the British Isles.

The grant will support five years of study by researchers at the Natural History Museum, London, and partner institutions. The team will investigate when people first arrived in Britain, and how the populations responded to environmental change. A particularly interesting question is why the country seems to have been uninhabited between 170,000 and 70,000 years ago.

Britain has some of the world's best archaeological sites from the Palaeolithic period, from about 500,000 to 12,000 years ago. In 1993, for example, a 500,000 yearold human shin bone was found at Boxgrove, near Chichester in West Sussex (see Nature 369, 311-313; 1994). But funding has been scarce for archaeology in recent years, researchers complain, and gravel extraction and coastal erosion are now threatening some of the most promising locations for exploration.

Archaeology "really has been neglected in the United Kingdom and many sites are being destroyed", says Simon Parfitt of the Institute of Archaeology at University College London. He hopes the grant will help to revive interest in the subject.

Chris Stringer, head of human origins at the Natural History Museum and the project's director, says that Britain's variable geography and climate make it ideal for studying how early humans adapted to environmental change. Stringer says the project will conduct some new excavations, but will focus mainly on re-examining the extensive collections of stone tools, fossil remains and animal bones that already exist at various universities and museums.

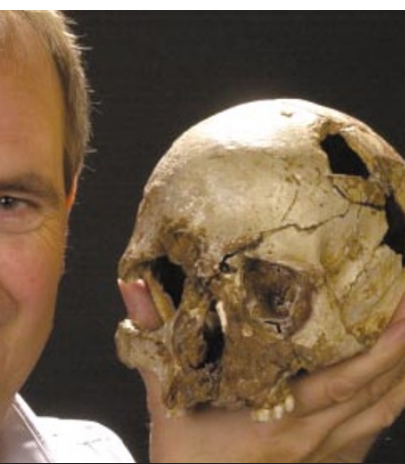

Bone ideal: Chris Stringer says Britain is a good place to study early human settlements.

\section{Crushing victory could help in quest for fusion energy}

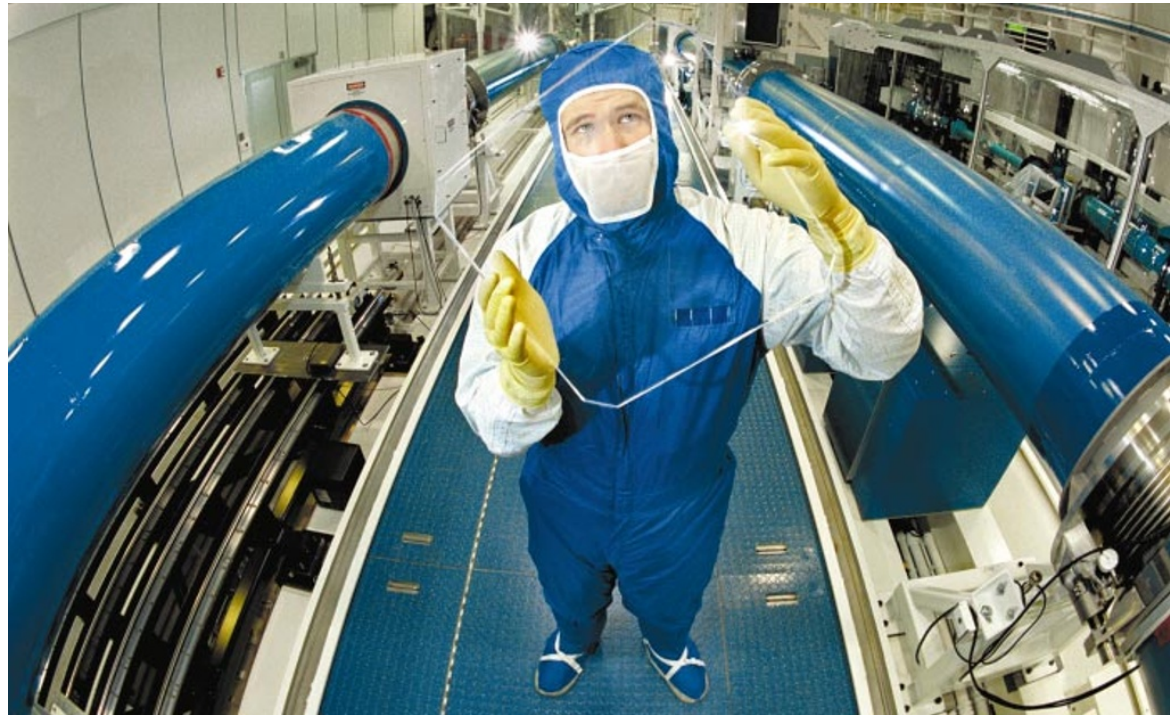

Laser gazer: part of the Beamlet, which is used to capture images of material compressed by X-rays.

William Triplett, Washington

Fusion researchers at Sandia National Laboratory in New Mexico have shown that an $\mathrm{X}$-ray machine, known as the Z-machine, can be used to compress a small plastic pellet uniformly, bringing hopes of achieving controlled nuclear fusion a step closer.

The researchers want to develop the Zpinch, as the machine's technique is known, to produce fusion energy. The technique already generates the world's most powerful laboratory X-rays. But until last month, the researchers hadn't been able to observe directly that the X-ray flash produced by their machine crushes its target pellet evenly.

They have now confirmed this by reconstructing the powerful Beamlet laser and using it to obtain images of the compressed pellet. Beamlet was first built at the Lawrence Livermore National Laboratory in California as a prototype for the National Ignition Facility now under construction there.

The laser image shows that the pellet was compressed uniformly, by a factor of two. "Pellets have been compressed before by more than that, and they will have to be compressed a lot more to achieve nuclear fusion," says Stephen Dean, president of Fusion Power Associates, a Maryland-based group that promotes fusion energy. But he says the finding is "a real advance" for the New Mexico laboratory.

The Sandia researchers now want to increase the laser energy during compression so that the temperatures and pressures exerted on the deuterium-filled pellet are closer to those at which fusion will occur.

Seen from above, Sandia's Z-machine looks like a wagon wheel, some 40 metres across. Its rim is surrounded by huge power capacitors, and the spokes consist of 36 aluminium and steel conductors that take power to the centre. There it is fed into extremely fine tungsten wires strung along the sides of a small cylinder.

When fired up, the capacitors send a current of 20 million amps through the conduits and into the tungsten wire. In the instant before the wires evaporate, the electrical current produces an extraordinarily powerful magnetic field, which in turn generates $\mathrm{X}$-rays. The project's researchers think these $\mathrm{X}$-rays could be channelled to produce controlled fusion, just as X-rays produce fusion in a hydrogen bomb.

Controlled nuclear fusion would require compression by a factor of about 20, says John Porter, manager of the Sandia project. He says he is confident that the Z-machine can achieve a factor of at least 10 .

Sandia researchers spent $\$ 13$ million reconstructing the Beamlet for the $\mathrm{Z}$ machine. Having used it to photograph the pellet, they want to shorten its laser pulse by a factor of 1,000 and use it to inject extra heat into the pellet. This project would cost a further \$30 million, the researchers say.

But even with better compression and extra heat, the existing equipment would probably fall short of achieving the selfsustaining fusion reaction that fusion researchers call ignition. "Theoretically [ignition] is within the realms of possibility," says Porter. "But we'd be doing this more as a proof of concept than an attempt to start a real fusion burn. We are excited by the possibilities, yes, but we do have to temper that with reality." 